\title{
Afinal, O QUe QUEREM AS MUlHeres?
}

\author{
Livia Barbosa*
}

\section{Resumo}

No Brasil e no mundo, as mulheres avançaram consideravelmente em vários setores. Este avanço se deu sempre na busca pela igualdade. Entretanto, como sugerem as pesquisas, este avanço não se deu na medida desejada. Ainda que sejam tão empreendedoras quanto os homens (e em algumas modalidades até mais do que eles), possuam uma média de anos de estudo maior, trabalhem mais e estejam com autoestima elevada, as distâncias a serem vencidas ainda são consideráveis. Além disso, elas continuam almejando um ideal romântico de parceiro, casamento para toda a vida, filhos e família. Neste contexto, a pergunta título me parece deslocada, com as dificuldades encontrando-se justamente na resposta, já que os homens não legitimam estes "quereres", e nem se mostram preparados a ponto de escolherem uma parceira que lhes seja igual. Considerando a autonomia de nossos quereres, nascidos de dinâmicas internas ao gênero ao qual pertencemos e condicionados pela sociedade e pelas mudanças que nela ocorrem, talvez a indagação mais adequada seja: "Afinal o que nós, homens e mulheres, queremos hoje?".

Palavras-chave: mulheres; "quereres"; igualdade.

\section{Abstract}

After All, WHAT DO WOMEN WANT?

In Brazil and the world, women have advanced considerably in various sectors. This breakthrough came when in the pursuit of equality. However, research suggests, this advance and gave no's as you want. Although they are as entrepreneurial as men (and in some manner even more than them) have an average years of schooling increased, more and work with self-esteem are high, the distances to be overcome are still considerable. Moreover, they are still aiming for an ideal romantic partner, marriage for life, children and family. In this context, the question title seems out of place, with the difficulty lies precisely in response, since it does not legitimize

* Diretora de Pesquisa do Centro de Altos Estudos da Escola Superior de propaganda e Marketing da Escola Superior de Propaganda e Marketing. 
these men "want", and not prepared to show the point of choosing a partner who will be the same. Given the autonomy of our desires, born of internal dynamics of the genre to which we belong and conditioned by society and the changes that occur in it, perhaps the more appropriate question is: "After all what we men and women want today?".

Keywords: women; "wanting"; equality.

\section{INTRODUÇÃo}

Afinal, o que querem as mulheres? Esta pergunta foi feita por Freud, no século XIX, depois de 30 anos de estudos sobre a alma feminina. Ela originou-se, segundo Kramer (2006), biógrafo de Freud, das reflexôes do pai da psicanálise sobre uma de suas pacientes: Ida Bauer. Ida tinha 15 anos e estava acometida de acessos de tosse nervosa e dificuldades para falar. A interpretação dada por Freud ao caso - assédio sexual de um amigo da família e a incapacidade do pai em protegê-la - era que o nervosismo e a afasia ocasionais da paciente eram fruto do seu desejo sexual inconsciente pelo molestador. A dificuldade em admiti-lo gerava os sintomas que Ida apresentava, em um claro processo histérico. A jovem rejeitou a interpretação de Freud e abandonou o tratamento. Considerando-se os valores da época, a sua pouca idade e o analista em questão, a atitude da jovem merece a nossa admiração pela sua coragem e segurança sobre os próprios sentimentos. Kramer (2006) relata, ainda, que Ida Bauer, posteriormente, enfrentou o próprio pai. Isto levou ao desaparecimento dos sintomas. Freud aceitou os fatos e formulou a famosa frase: afinal, o que querem as mulheres? Qual frase? Pelo visto esta jovem sabia o que queria mais do que Freud sabia o que ela tinha.

A frase ficou sem a resposta de Freud. Contudo, depois dele a frase já recebeu inúmeras interpretações por parte de psicanalistas, psicólogos, literatos e intelectuais de modo geral sobre o que o pai da psicanálise queria efetivamente dizer. Uma destas interpretaçōes, que eu considero interessante, era de que com esta frase Freud admitia a legitimidade do desejo feminino. Não creio que muitas de nós, mulheres contemporâneas, lhe atribuiríamos este crédito positivo. Pelo desenrolar do caso de Ida Bauer, poderíamos levantar a hipótese de que Freud estaria perplexo por a jovem não estar lisonjeada pelas atenções do molestador. Afinal de contas, o que mais as mulheres poderiam desejar do que a atenção masculina na Viena do século XIX?

Além das interpretações sobre o que Freud queria efetivamente dizer com a frase, várias foram as tentativas de responder a esta pergunta. Encontramos, por exemplo, livros como O que as mulheres querem? (2001) de Erica Jong, escritora 
norte-americana famosa por seu livro Fear offlying (1973) sobre sexualidade feminina na década de 1970. Em seguida, passamos pelo filme com Mel Gibson "O que as mulheres pensam”. E terminamos com pesquisas de psicologia experimental (Chivers, 2007). A série televisiva da Rede Global, realizada no final de 2010, é mais uma dessas tentativas, agora no ramo do entretenimento.

Não tenho pretensóes de responder a esta frase, mesmo sendo mulher e sabendo o que quero da minha própria vida. Mas não me furtarei de refletir sobre ela. Eu começo pelas várias possíveis entonações da frase, que determinam sentidos inteiramente distintos de acordo com a forma como ela é pronunciada. Se eu falo e enfatizo a palavra afinal e emprego um tom de impaciência, o sentido imediato de quem a ouve é de uma certa exasperação, de exaustão psicológica, como se, depois de várias idas e vindas, de discussōes infindáveis, não tivéssemos chegado a qualquer conclusão. É a frase do desespero!

Se, por outro lado, pronuncio a mesma frase de forma a que a ênfase recaia sobre a palavra mulheres, o sentido sugerido é de uma solução para uma demanda existente da parte daqueles que querem (as mulheres) por aquele(s) que se encontra(m) pressionado(s) e tem(têm) o poder de conceder ou não aquilo que o outro deseja. É uma frase que sinaliza reivindicações, poder e negociações!

O primeiro exemplo de entonação (sobre a palavra afinal) nos remete a uma antiga tradição de se descrever as mulheres como seres complexos, contraditórios. Seres que mudam de ideia com frequência, que não sabem o que desejam e, portanto, dos quais não se sabe o que esperar. Esta interpretação sobre as mulheres aparece, historicamente, travestida de uma exasperação condescendente, mas que caracteriza justamente o encanto e o charme do sexo feminino. É o tom adotado pelas comédias românticas hollywoodianas em publicaçōes do gênero "Os homens são de Marte e as mulheres são de Vênus" (1996), ou ainda em programas de TV que apresentam o homem vitimizado pela contradição feminina. Piadas ou comentários do tipo "quando a mulher diz sim ela de fato quer dizer não e viceversa” são típicos desta vertente.

O segundo exemplo (enfatizando a palavra mulheres) nos remete a um entendimento da condição feminina como um problema. Ou seja, algo do qual tenho que me livrar para tratar de coisas mais importantes. Embora possa ser, à primeira vista, uma atitude exclusivamente masculina, não o é. Muitas mulheres também a adotam. Na verdade o termo mulher é substituível por qualquer outro, principalmente em se tratando de inferiores estruturais: trabalhadores, operários, empregadas domésticas ou "uma fulana qualquer". É o tom usado quando superiores estruturais se sentem pressionados pela base. O que está por trás é a ideia de que aquele que tem poder de dar já deu tudo aquilo que acha que devia 
ser dado e se encontra no limite de suas concessões. É o tom do "resolve e tira logo do meio do caminho".

Seria possível pensar em outras entonações, com outros sentidos subjacentes, mas este seria um exercício interminável. Por isso, minha proposta é decompor a pergunta do ponto de vista gramatical. E com isto tentar encaminhar outras reflexões que possam parcialmente responder a frase. Vejamos: quem quer quer alguma coisa de alguém. Neste sentido, temos que pensar: a que mulheres o querem da pergunta se refere? Brancas, negras, nível universitário, brasileiras, norte-americanas entre outras? Ou existiria uma essência feminina que nivelaria todas estas diferenças e o querer das mulheres seria um único querer?

Além do "de que mulheres estamos falando?" temos que considerar qual o objeto do querer destas mulheres. $\mathrm{O}$ objeto é a carreira, o reconhecimento social, o poder ou é o afeto, a sexualidade ou tudo isso junto? E em que proporções queremos isso tudo em nossas vidas? Quem detém o poder de conceder ou não este querer? $\mathrm{O}$ estado, os homens, a comunidade, a sociedade ou este querer não é um caso de concessão, mas de conquista por parte das mulheres?

Mesmo com todas as especificações indicadas a pergunta não receberia uma resposta satisfatória e definitiva. $\mathrm{Na}$ medida em que selecionamos um grupo, um objeto ou um sujeito, podemos deixar outros tantos de fora. Para resolver este dilema teríamos que estender esse exercício infinitamente em um relativismo irritante, que não nos permite afirmar nada sobre coisa alguma, pois, além do medo intelectual que ele gera de sermos os sujeitos de alguma exclusão, tudo é muito particular e único, como afirmam os pós-modernos. Minha perspectiva é, contudo, examinar onde "estes particulares" se encontram. Parto do princípio de que essa imensa particularidade, conjugada a uma crescente universalidade, caracteriza a sociedade contemporânea. Enquanto as particularidades se objetivam em diferenças e demandas específicas de grupos particulares, a universalidade se constitui quando se consegue abarcá-las no interior de uma instituição/valor. Assim, estes últimos se tornam universais quando precisamente englobam uma crescente particularidade. Tomemos como exemplo a noção de "direitos". Inicialmente incluía apenas homens, brancos, anglo-saxões protestantes e excluía mulheres, operários, camponeses entre outros. Hoje, a noção de direitos inclui todo e qualquer grupo humano, a despeito de suas diferenças específicas, e até mesmo os direitos da natureza operados pelo instituto de stewerdship (Nash,1989).

No caso da pergunta "Afinal, o que querem as mulheres?", uma resposta única talvez seja uma impossibilidade devido aos infinitos "quereres" das diversas "mulheres". Não obstante, existe um princípio difundido pelo movimento feminista na sua versão das décadas de sessenta e setenta que aspira à universalidade e 
tem se aproximado dela: a ideia de igualdade. Hoje, ela se apresenta em todas as sociedades do mundo como uma demanda à qual estas têm que responder não só perante as suas "mulheres", mas, também, perante a comunidade internacional. Mesmo que esta igualdade seja enfatizada culturalmente de formas distintas e específicas (Barbosa, 1999). Mesmo que muitas mulheres e muitos homens não a subscrevam como um valor pessoal, cada vez mais ela não depende de nossas identificações subjetivas e individuais, na medida em que crescentemente se torna uma instituição que abriga todas as mulheres independentemente de suas especificidades e características.

É a partir desta posição - da igualdade como o locus do encontro das diversidades - que julgo que a questão inicial possa ser respondida.

\section{Mulher e PODER}

Temos hoje, simultaneamente, no mundo, 14 mulheres liderando os destinos políticos de diferentes países $^{2}$. Se acrescentarmos a esta lista ministras, Secretárias de Estado e todas as governadoras e prefeitas que dirigem estados e municípios e deputadas e senadoras, membros de parlamentos de todo o mundo, esse número chega à casa das centenas ou dos milhares. Se levarmos em consideração também as últimas décadas e incluirmos mulheres que estiveram no poder liderando diretamente uma sociedade - como Michelle Bachelet, no Chile, e outras que tinham a decisão dos destinos de milhões de pessoas atrelada as suas posições ideológicas e posicionamento político, como era o caso da Secretária de Estado Madeleine Albright dos Estados Unidos e ex-chefes de estado como Indira e Sonia Ghandi, Golda Meir (Israel) e muitas outras - e compararmos com os séculos anteriores certamente o resultado é extremamente positivo.

Ainda assim, no contexto dos 180 países existentes no mundo, o número de mulheres na liderança direta é de menos de 10\%. Precisamos, contudo, considerar que muitas vezes a oportunidade para uma participação institucional política das mulheres já está até mais avançada do que o número delas em posições oficiais nos indicam. Por exemplo, no Brasil, os partidos políticos são obrigados a terem uma cota de mulheres como candidatas. Entretanto, nenhum deles consegue preenchê-la. Mesmo que víssemos nisso mais uma demonstração de discriminação em relação às mulheres, o fato é que o número de mulheres registradas em partidos políticos ainda é menor do que o dos homens. Registrar-se, querer participar mais ativamente é uma decisão que só as próprias mulheres podem tomar. Portanto, o que os números indicam é que mulheres detendo poder e autoridade política não 
é mais uma novidade na sociedade contemporânea, mas ainda não chega a ser uma obviedade, menos ainda uma carreira e/ou objetivo de vida para a maioria.

Se considerarmos o contexto organizacional, um outro quadro se delineia. Um número maior de mulheres emprega mais pessoas em seus próprios negócios do que as 500 maiores empresas. Entretanto, de acordo com um estudo divulgado pelo Fórum Econômico Mundial em 2009, somente 5\% das presidências de grandes empresas mundiais são ocupadas por mulheres. Nesta pesquisa, o FEM (WEF) entrevistou responsáveis pelos setores de Recursos Humanos de 600 grandes empresas ao redor do mundo e constatou que as mulheres não estão no topo na maioria delas. Esta mesma pesquisa avaliou também o total de mulheres trabalhando nas grandes empresas. O Brasil se encontra em uma posição intermediária (35\%) de mulheres empregadas. Os Estados Unidos aparecem em primeiro lugar, com 52\% de mulheres empregadas, seguidos por Espanha, Canadá e Finlândia. Mesmo assim, nos Estados Unidos as mulheres ocupam menos de 643 de um total de 6081 assentos em conselhos de diretoria das 500 maiores empresas, em torno de reduzidos 11\%. Ou seja, as mulheres encontram-se instaladas nas camadas médias das organizações e do mercado de trabalho, mas não no seu topo. $\mathrm{O}$ famoso glass ceiling continua existindo. Mas a pergunta que se segue, considerando-se o nível de educação mais elevado das mulheres em comparação com os homens, é: o que explicaria a manutenção do glass ceiling? Discriminação masculina? Medo do sucesso por parte das mulheres? Desinteresse pelo poder?

Em pesquisa realizada por mim em uma grande multinacional no final da década de 1990, várias mulheres, executivas a um passo de serem diretoras, presidentes e vice-presidentes de grandes empresas, exprimiram com bastante clareza as dúvidas que as incomodavam. O que mais se salientava neste contexto era o sentimento crescente de perda de liberdade. $\mathrm{O}$ dinheiro e o prestígio pareciam não compensar uma vida destituída de "cor" - como uma delas me colocou -, do direito de poder ir e vir, da possibilidade de inverter a rotina. Entre suas falas está o seguinte exemplo: “os homens não têm esta opção, mas nós ainda a temos, por que perdê-la?". Seriam, pois, a liberdade e a autonomia pessoais valores mais importantes para as mulheres do que o poder e a autoridade formalmente constituída?

Entretanto, estes números sobre mulheres no topo das organizações, quando analisados por setor, sinalizam para dinamismos distintos em diferentes áreas. Por exemplo, pesquisa da Computerworld/EUA (2010) indica que entre as mil maiores empresas do mundo o número de mulheres que ocupa a posição de CEO ou vice-presidente de TI saltou de 12\%, em 2007, para 16,4\%, no último ano. De acordo com o mesmo levantamento, apesar do aumento de participação das profissionais do sexo feminino, ainda é raro encontrar uma mulher em cargos 
técnicos como a diretoria de infraestrutura. A pesquisa informa, ainda, que 36,9\% das mulheres que ocupam cargos de liderança na área de TI se destacam nas tarefas que dependem do trabalho em equipe, enquanto que esse índice cai para 19\% entre os homens na mesma posição. Em contrapartida, 81\% dos CEOs do sexo masculino ganham projeção por suas contribuições individuais, enquanto que no caso das representantes do sexo feminino esse índice é de 63,1\%.

As mulheres adicionam valor quando no comando das empresas? As últimas pesquisas indicam que sim. Um levantamento da Catalyst, ONG norte-americana especializada na participação das mulheres no mercado de trabalho, mostrou que, no universo das 353 maiores companhias listadas pela revista Fortune, as empresas com maior número de mulheres em sua cúpula tinham uma performance financeira em média 35\% melhor do que as empresas com pouca ou nenhuma mulher no comando.

A Catalyst explica que o resultado não se deve a uma suposta superioridade do sexo feminino na liderança dos negócios, mas à heterogeneidade de pensamentos e visões que a mistura dos sexos proporciona. Em outras palavras: uma empresa com homens e mulheres na chefia tem uma visão muito mais ampla do que aquela em que os homens dominam.

No Brasil, em pesquisa de 2010 realizada pela empresa Sophia Mind ${ }^{3}$ com 340 brasileiras das cinco regiōes do país, com idade entre 25 e 50 anos e nível superior completo, constatou-se que $71 \%$ das mulheres se planejam para atingir seus objetivos profissionais e que 37\% delas visam chegar à presidência de uma empresa. Das entrevistadas, 30\% estão em cargos de liderança - coordenadoras, gerentes e diretoras. A pesquisa revelou ainda que $47 \%$ das mulheres gostariam de estar em um novo emprego daqui a cinco anos. Já 39\% delas acreditam que estarão na mesma empresa, mas em um ou mais cargos acima da posição atual. Tendo o crescimento profissional como um objetivo, $81 \%$ das mulheres casadas dessa amostra afirmam não terem alterado seus planos de carreira após o casamento. Dentre as que são mães, 63\% também não mudaram os seus planos profissionais após o nascimento dos filhos, mas $24 \%$ acreditam que alcançar as metas a que se propuseram tornou-se mais difícil.

Mas, se o Brasil não se destaca em relação à situação da mulher em posições de liderança empresarial, acredito que esta situação não deverá permanecer a mesma por muito mais tempo. De acordo com o Global Gender Gap Index 2008, um ranking da ONU que avalia a diferença entre homens e mulheres em 128 países, o Brasil aparece na primeira posição, juntamente com alguns outros países, no quesito "acesso à educação". De fato, as mulheres representam cerca de $55 \%$ dos matriculados nas graduações presenciais no Brasil, refletindo a proporção entre os gêneros na população em idade universitária. 
Nesse contexto, o ensino à distância (EAD) tem sido um grande aliado feminino: as mulheres são a grande maioria neste setor. Elas representam de 70 a $80 \%$ do total de matriculados em graduações nessa modalidade. Esses dados se repetem também no Estado de São Paulo, segundo o Instituto Nacional de Estudos e Pesquisas Educacionais Anísio Teixeira. Além disso, 61.2\% das mulheres têm mais de 11 anos de escolaridade, face a 53.2\% dos homens. Entretanto, as mulheres ainda predominam em áreas tradicionalmente femininas como educação (81\%), saúde/bem-estar social (74\%), humanidades e artes (65\%).

Considerando que as mulheres são em maior número nos bancos universitários e possuem um maior grau de escolaridade, é difícil imaginar que elas não galguem posições mais altas, mesmo que seja pela ausência de homens qualificados para fazê-lo. Mesmo que este não seja o cenário que se desejaria - ou seja, as mulheres ascenderem não por falta de elementos masculinos qualificados, mas sim por reconhecimento de sua capacidade individual -, a prática termina por derrubar o mito.

\section{Mulheres, PODER ECONÔMICO E CONSUMO}

E como estamos no mundo da economia e do mercado? No quesito empreendedorismo, as mulheres se destacam em relação aos homens (Global Enterpreneurship Monitor, 2009). Dos empreendedores brasileiros, 54\% são mulheres e 47\% homens. Segundo o mesmo relatório, "a mulher brasileira é historicamente uma das mais empreendedoras do mundo" (Global Enterpreneurship Monitor, 2009: 9). Outro aspecto relevante deste relatório é que, ao longo do período analisado em 2009, é a primeira vez que a proporção de mulheres empreendedoras por oportunidade supera a proporção de homens na mesma condição. Em relação ao poder econômico, recente pesquisa levada a cabo pelo Mosaic Serasa Experian (2010) - a partir de uma base de dados de 135 milhões de pessoas do Censo do IBGE - dividiu esta população em 10 grupos e 39 subgrupos que melhor qualificam as classes ABCDE. De acordo com os dados estatísticos apresentados, a mulher está presente nos segmentos mais ricos da população. Mas o mais importante é que a mulher é rica não apenas porque vive em uma família de boas condições financeiras, mas porque ela é um agente econômico. Por exemplo, no grupo Rico, Sofisticados e Influentes (a), que corresponde a $1.86 \%$ da população analisada e em números absolutos a 2.5 milhões de pessoas, as mulheres compreendem 1 milhão destas. No segmento Empresários de Sucesso das Grandes Cidades (A1), as mulheres representam $39 \%$, o que equivale a 611 mil executivas. No grupo Executivos e 
Formadores de Opinião (A2), elas são 36\%, no grupo Vida Contemporânea elas perfazem 46\% e somam cerca de 690 mil. No grupo Empregos Estáveis (B5), elas são $59 \%$, o que dá um total de 1,1 milhão de mulheres. No grupo Aposentadoria dos Sonhos (B6), as mulheres são maioria com 54\% do total e no Jovens Promissores (C8), 57\%, o que significa em números absolutos 1.1 milhões de pessoas. Em Profissionais em Ascensão (E14), as mulheres perfazem 55\% e no de Jovens em Busca de Oportunidades (E16), 60\%. Se lermos estes números estrategicamente e verificarmos a faixa etária que os compõe, temos que, além de as mulheres participarem em todos os grupos em proporções acima de 35\%, chegando em alguns até em $60 \%$, sendo seus recursos econômicos advindos do próprio trabalho, os dois últimos grupos - Profissionais em Ascensão e Jovens em Busca de Oportunidades - sinalizam que as mulheres estão engajadas e determinadas a obterem uma maior parcela da riqueza econômica da nação. Estão buscando tanto ascensão profissional quanto mais oportunidades. Isso significa que elas não só "foram a luta mas continuam na luta com ainda mais intensidade".

No mercado consumidor brasileiro, a mulher repete a sua trajetória histórica de personagem central por definição da sociedade de consumo (Miller, 1981; Williams, 1982). No mundo as mulheres controlam U\$ 20 trilhôes de dólares e o previsto é que alcancem 28 trilhões em 2015. No entanto, a massa salarial feminina - que no Brasil é de R $\$ 576$ bilhões - é praticamente a metade do seu consumo. Como explicar esta matemática financeira? A resposta encontra-se no fato de que em grande número de países, como o Japão, as mulheres são responsáveis pela gestão do orçamento familiar. Aquele espaço da vida doméstica que Miller (2005) denominou de cauda do capitalismo. Um espaço a que poucos prestam atenção, pois é o local onde decisões consideradas de pequena monta, rotineiras e de importância secundária quando comparadas às decisões políticas, financeiras e de políticas públicas são tomadas. O Brasil não é exceção: R 1.90 trilhões é o gasto em consumo da família brasileira. 66\% destes, ou seja, 1.25 trilhões, são de responsabilidade das mulheres, sendo $\mathrm{R} \$ 0.77$ trilhôes gastos diretamente $\mathrm{e}$ $\mathrm{R}$ \$ 0.48 trilhôes indiretamente. Mas em que produtos as mulheres mais gastam? Que mercados elas dominam? Segundo uma pesquisa realizada pela Sophia Mind (2010), constatou-se que o setor em que as mulheres mais gastam são alimentação, seguido de vestuário e acessórios, educação dos filhos e alimentação fora de casa. Esta mesma pesquisa constatou que as mulheres controlam em mais de 50\% as compras nos seguintes mercados: vestuário feminino e maquiagem, beleza e cuidados pessoais (cabelo, pele) e produtos para a casa (alimentação, limpeza, higiene etc). Cuidados com os filhos (material escolar, atividades extra-classe), lazer, serviços médicos, serviços para a família, compra ou gastos familiares são mercados 
de grande influência feminina. Já os mercados de cuidados pessoais masculinos e de carros são considerados mercados de decisões mais equilibradas, nos quais as mulheres influenciam em quase $50 \%$ as decisões de compra. O que estes números indicam? Uma proeminência indiscutível da mulher nas decisões de compra na cauda do capitalismo avançando para a cabeça do mesmo. Mas como este espaço é hoje fundamental no que concerne à sustentabilidade das sociedades, qualquer política pública a este respeito tem que levar em conta as mulheres. São as mulheres que podem reverter inúmeros hábitos culturalmente arraigados de práticas domésticas de limpeza, higiene e alimentação que têm impactos profundos no consumo de bens (Barbosa, 2004).

Mas seria enganador supor que as mulheres se restringem à "cauda do capitalismo". Elas são também as maiores consumidoras de produtos culturais, ou seja, estão presentes na "cabeça do capitalismo". Segundo pesquisa realizada em parceria pela Fecomercio, Ipsos e Public Affair em 2008 em 1000 domicílios de 70 cidades em 9 regiões metropolitanas, as mulheres são aquelas que mais valor dão à leitura. Dentro da média de 5,1 livros lidos em 2008, elas leram 5,5 enquanto os homens 4,7. À pergunta acerca do que mais gosta de fazer, por ordem de preferência, $69 \%$ das mulheres disseram que preferem ler um livro, contra $61 \%$ dos homens. Na projeção futura que fizeram para seus hábitos em 2009 elas também deram prioridade à leitura, com $45 \%$ das preferências em comparação a $41 \%$ dos homens.

As mulheres estão também consumindo on line. De 2001 até o momento, o crescimento do comercio on line foi de $2000 \%$, segundo o e-bit, e $55 \%$ dos e-consumidores são mulheres. O valor médio dos gastos femininos em compras pela internet é de $\mathrm{R} \$$ 465,00 mês, sendo os produtos mais adquiridos: livros, revistas e eletrônicos. Isto confirma a preferências das consumidoras por produtos culturais.

\section{Mulheres e homens}

Mas esta proeminência no consumo e o avanço em outras áreas são acompanhados de uma visão positiva sobre si mesma e sobre a sua condição feminina? Ao que tudo indica, sim. Em uma pesquisa realizada pela Toledo Associados (2010) pelo dia internacional das mulheres, $77 \%$ das 125 entrevistadas na cidade de São Paulo, de todos os segmentos de renda e níveis educacionais, entre 18 e 60 anos, se consideravam mais inteligentes que os homens. Além disso, $74 \%$ se disseram menos corruptas, $94 \%$ mais intuitivas, $87 \%$ mais organizadas e $82 \%$ mais competentes no trabalho em relação ao gênero masculino. Elas também reconheciam, 
em $77 \%$ dos casos, que eram discriminadas, visto que os homens ganhavam mais, tinham mais oportunidades e reconhecimento profissional. Assim, 54\% clamavam por mais igualdade.

Essa visão das mulheres comparativamente aos homens recebe respaldo nos números de outras fontes no que concerne às horas trabalhadas e às diferenças salariais. Segundo a pesquisa mensal do IBGE (março de 2010), as mulheres com maior nível educacional trabalham mais horas semanais e recebem $72.3 \%$ dos salários dos homens. Portanto, não é de admirar que a falta de tempo seja uma das principais preocupações das mulheres, que querem ser reconhecidas em seus diferentes papéis - mãe, esposa, profissional. Elas acumulam funções dentro e fora do lar. Além disso, elas não admitem serem mães apenas razoáveis ou profissionais medianas. O resultado disso é que 57\% das entrevistadas na pesquisa da Sophia Mind (2010) afirmam que a vida pessoal e a profissional não estão em equilíbrio. Dentro da mesma linha, $86 \%$ das mulheres entrevistadas pela Toledo Associados (2010) consideram a sua vida estressante, ou seja, 44\% estressante e $42 \%$ extremamente estressante.

Mesmo sentindo-se pressionadas, as mulheres não estão dispostas a abrirem mão do seu lado afetivo e familiar. Dessa forma, 91\% pretendem se casar, 98\% consideram a família muito importante, $81 \%$ acreditam que o seu futuro casamento irá durar para sempre, $73 \%$ acreditam que já encontraram ou pretendem encontrar o homem ideal (Sophia Mind, 2010).

Quando perguntadas sobre de que atividades não abririam mão em função da carreira, 71\% citaram cuidar da saúde, $60 \%$ escolheram os momentos de lazer com a família e 57\% escolheram não abrir mão da maternidade (Sophia Mind, 2010). E as prioridades indicadas confirmam isso. Até os 25 anos as mulheres focam na carreira e na educação; dos 26 aos 40 anos, estão interessadas em ter filhos e se casar; de 40 anos em diante nas mesmas coisas anteriores, caso elas ainda não tenham realizado ambas (Sophia Mind/Mulheres entre 28/29 anos).

As mulheres estão perseguindo com clareza seus objetivos educacionais, profissionais e de carreira, como as estatísticas indicam, e ao mesmo tempo mantêm o ideal romântico de casamento com um parceiro ideal e de filhos. Por outro lado, os homens latino-americanos, inclusive os brasileiros, não parecem estar entusiasmados com estas conquistas e objetivos femininos. Pesquisa realizada pelo Center for International Development da Universidade de Harvard (2010), intitulada, sugestivamente, Schooling can't buy me love, indica que as mulheres preparadas e com alto nível educacional casam menos do que as suas congêneres com menor nível educacional e do que os homens em igual situação. A pesquisa constata, ainda, que as mulheres latino-americanas casam com homens menos preparados 
educacionalmente do que elas quando comparadas a mulheres de outras regióes do mundo e que os latinos americanos atribuem, ainda, um valor maior para as esposas que ficam em casa. Concluindo, as mulheres preparadas e de alto nível educacional tendem a casar hipogamicamente. A educação não é considerada pelos latino-americanos como um capital matrimonial.

\section{OBSERVAÇÕES FINAIS}

Considerando as diferentes pesquisas e os números indicados anteriormente, é possível constatar que no Brasil e no mundo as mulheres avançaram consideravelmente em vários setores. Todos estes avanços sinalizam para uma busca pela igualdade entre elas e os seus congêneres masculinos. Entretanto, como alguns dados apontam, elas têm plena clareza de que este avanço não é o que deveria ser. Embora as mulheres sejam tão empreendedoras quanto os homens - e em algumas modalidades até mais do que eles -, possuam uma média de anos de estudo maior do que eles, encarem um número maior de horas trabalhadas e estejam com uma autoestima alta por se perceberem em vários aspectos melhores que seus congêneres masculinos, as distâncias a serem vencidas ainda são consideráveis. Mesmo assim elas não abandonaram o ideal afetivo, familiar e maternal. Neste contexto, a frase "Afinal, o que as mulheres querem?" me parece deslocada, pois elas parecem sabê-lo. Ao que tudo indica, a dificuldade encontra-se não na pergunta, mas na resposta: as mulheres querem tudo, embora, no que concerne ao território ao Sul do Equador, os homens não legitimem todos estes "quereres" e, por conseguinte, não se mostrem dispostos ou preparados para aceitarem mulheres tão "desejosas" a ponto de escolherem uma parceira que lhes seja um igual.

Cabe perguntarmos, então: afinal, o que os homens querem? Esta mesma pergunta genérica feita em relação às mulheres nunca é feita aos homens. A razão disso, incluindo o próprio Freud, é que partimos de um pressuposto, jamais contestado, de que os homens sabem o que querem e estão satisfeitos com o que querem e com o que têm. Pressuposto igualmente valorativo e equivocado como é supor que as mulheres não sabem o que querem. Outro aspecto é imaginarmos que os nossos quereres são autônomos, nascidos de uma dinâmica interna ao gênero a que pertencemos. Todos os "quereres", sejam estes de quem for, estão condicionados pela sociedade e pelas mudanças que nela ocorrem. Esse é, especialmente, o caso da sociedade contemporânea, profundamente reflexiva, na qual todos nós estamos envolvidos e comprometidos no monitoramento das nossas vidas cotidianas de forma permanente, sempre nos refazendo ou planejando fazê-lo (Giddens, 1990). 
Assim sendo, talvez a frase mais adequada fosse: afinal o que nós, homens e mulheres, queremos hoje?

\section{REFERÊNCIAS}

Barbosa, L. (1999). Igualdade e meritocracia. Rio de Janeiro: Fundação Getulio Vargas.

Barbosa, L. (2004). Cleanness, pollution and disgust in modern industrial society. Journal of Consumer Culture, 4 (3), 385-405.

Berger, D. (2009, 22 de janeiro). What do women want? The New York Times.

Fecomercio, Ipsos e Public Affair. (2008). Perfil do consumo de cultura dos brasileiros. Rio de Janeiro.

Fórum Econômico Mundial-FEM (2009). The Brazil competitiveness report. Rio de Janeiro.

Jong, E. (1973). Fear of flying. New York: Holt, Rinehart \& Winston.

Jong, E. (2001). O que as mulheres querem? São Paulo: Record.

Giddens, A. (1990). The consequences of modernity. Stanford: Stanford University Press.

Global Entrepreneurship Monitor e IBOPE (2009). Empreendedorismo no Brasil. Relatório Executivo.

Gray, J. (1996). Os homens são de Marte e as mulheres são de Vênus. Rio de Janeiro: Editora Rocco.

Kramer, P. (2006). Freud: inventor of the Modern Mind. New York: Eminent Lives.

Miller, D. (2005). Acknowledging consumption. New York: Routledge.

Miller, M. B. (1981). The bon marche. Princenton: Princeton University Press.

Mosaic Serasa Experian. (2010). Pesquisa que cruza os dados cadastrais do Serasa Experian, do Censo do IBGE e da Pesquisa Nacional de Amostra Domiciliares. Retirado de: <www. serasaexperian.com.br/release/noticias/2010/noticia_00081.htm>.

Nash, R. (1989). The rights of nature. Madison: University of Winsconsin Press.

Petterie, A., \& Maletta, B.(2010). Poderosas consumidoras. In: <http://www.sophiamind. $\mathrm{com} />$.

Williams, R. (1982). Dream world: mass consumption in late nineteenth century. Los Angeles: University of California Press.

\section{Notas}

1 Este artigo está baseado na palestra proferida pela autora na Pontifícia Universidade Católica do Rio de Janeiro, em novembro de 2010, a convite do departamento de psicologia desta 
universidade e de Globo Universidade. O artigo mantém o tom coloquial da palestra.

2 São elas: Dilma Roussef (Brasil), Cristina Kirchner (Argentina), Laura Chincilla (Costa Rica), Ellen Johnson Sirleaf (Libéria), Pratiba Patil (Índia), Gloria Arroyo (Filipinas), Mary McAleese (Irlanda), Tarja Halonen (Finlândia), Micheline Calm Rey (Parlamento Suíço), Vaira Vike-Freiberga (Letônia), Angela Merkel (Alemanha), Helen Clark (Nova Zelândia), Begum Khaleda Zia (Bangladesh), Maria do Carmo Silveira (São Tomé e Príncipe).

3 Sophia Mind é uma empresa do Bolsa de Mulher dedicada à inteligência de marketing e tem como foco o conhecimento das mulheres por meio de pesquisas e análises de mercado. Todos os dados citados aqui podem ser encontrados no livro publicado com os resultados desta pesquisa nas referências bibliográficas.

Aceito para publicação em 28 de outubro de 2010 